
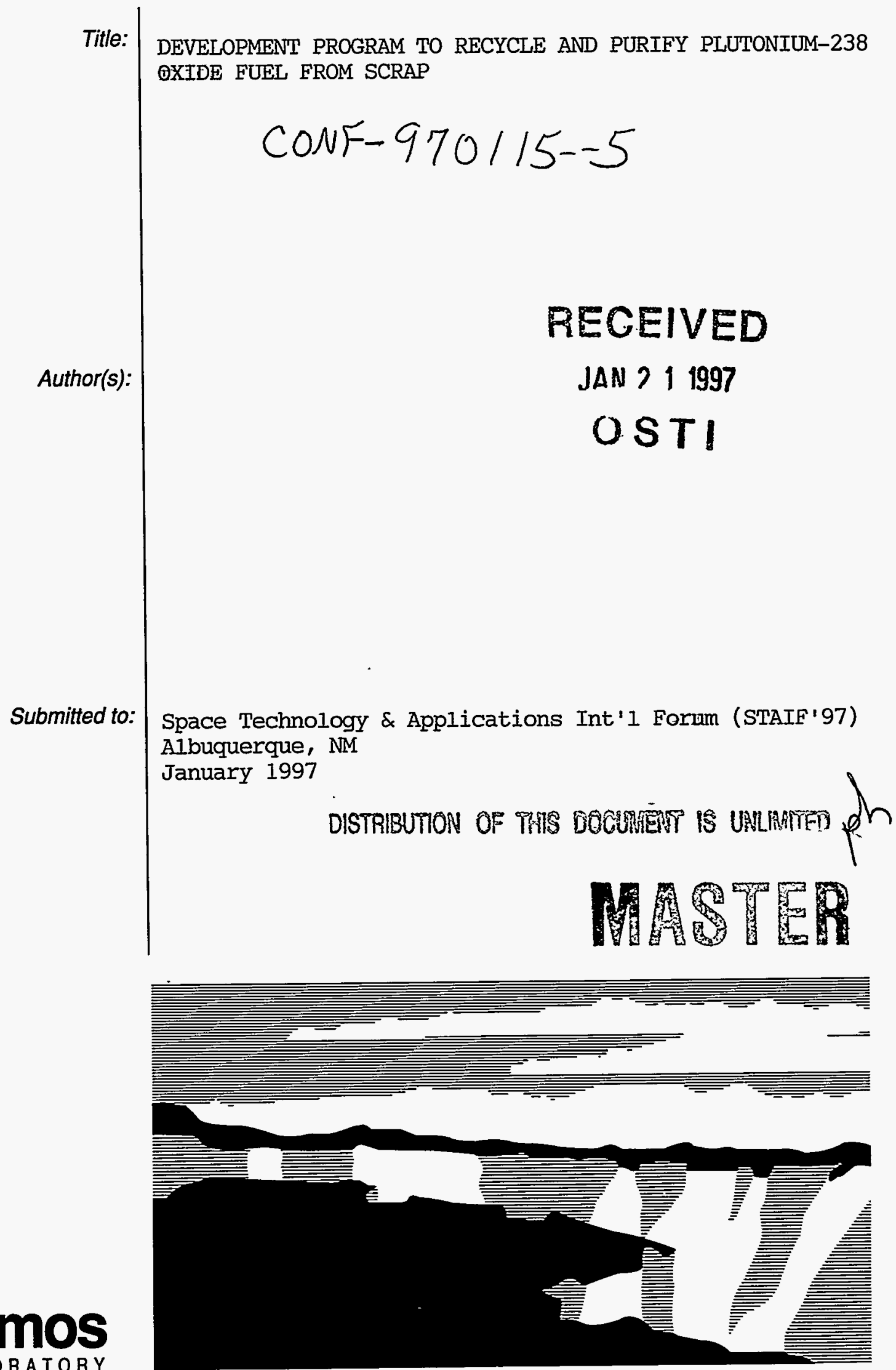

Los Alamos National Laboratory, an affirmative action/equal opportunity emplóyer, is operated by the University of California for the U.S. Department of Energy Los Alamos National Laboratory, an affirmative action/equal opportunity employer, is operated by the University of California the publish or reproduce the published form of this contribution, or to allow others to do so, for U.S. Government purposes. The Los Alamos National Laboratory requests that the publisher identify this article as work performed under the auspices of the U.S. Department of Energy. 


\title{
DEVELOPMENT PROGRAM TO RECYCLE AND PURIFY PLUTONIUM-238 OXIDE FUEL FROM SCRAP
}

Louis D. Schulte, Gary L. Silver

Larry R. Avens and Gordon D. Jarvinen

Advanced Technology Group NMT-6

Nuclear Materials Technology Division

Mail Stop E510

Los Alamos National Laboratory

Los Alamos, NM 87545.

\author{
Jacob Espinoza, Elizabeth M. Foltyn \\ and Gary H. Rinehart \\ Actinide Ceramics and Fabrication Group NMT-9 \\ Nuclear Materials Technology Division \\ Mail Stop E502 \\ Los Alamos National Laboratory \\ Los Alamos, NM 87545.
}

\begin{abstract}
Nuclear Materials Technology (NMT) Division has initiated a development program to recover \& purify plutonium-238 oxide from impure sources. A glove box line has been designed and a process flowsheet developed to perform this task on a large scale. Our initial effort has focused on purification of ${ }^{238} \mathrm{PuO}_{2}$ fuel that fails to meet General Purpose Heat Source (GPHS) specifications because of impurities. The notable non-actinide impurities were silicon and phosphorus, but aluminum, chromium, iron and nickel were also near or in excess of limits specified by GPHS fuel powder specifications. Among actinide impurities, uranium is of paramount concern because ${ }^{234} \mathrm{U}$ is the daughter of ${ }^{238} \mathrm{Pu}$ by alpha decay, and is the largest actinide impurity.

An aqueous method based on nitric acid was selected for purification of the ${ }^{238} \mathrm{PuO}_{2}$ fuel. All aqueous processing used high purity reagents, and was performed in PTFE apparatus to minimize introduction of new contaminants. Impure ${ }^{238} \mathrm{PuO}_{2}$ was first dissolved in refluxing $\mathrm{HNO}_{3} / \mathrm{HF}$ and then the solution was filtered. The dissolved ${ }^{238} \mathrm{Pu}$ was adjusted to the trivalent state by an excess of reducing reagents to compensate for radiolytic effects, precipitated as plutonium(III) oxalate, and recovered by filtration. The plutonium(III) oxalate was subsequently calcined to convert the plutonium to the oxide.

Decontamination factors for silicon, phosphorus and uranium were excellent. Decontamination factors for aluminum, chromium, iron and nickel were very good. The purity of the ${ }^{238} \mathrm{PuO}_{2}$ recovered from this operation was significantly better than specifications.

Efforts continue to develop the capability for efficient, safe, cost-effective, and environmentally acceptable methods to recover and purify $238 \mathrm{PuO}_{2}$ fuel in a glovebox environment. Plutonium-238 materials targeted for recovery includes impure oxide and scrap items that are lean in $238 \mathrm{Pu}$ values.
\end{abstract}

\section{INTRODUCTION}

Plutonium-238 is an excellent radioisotope for heat source applications in space because of availability, power density, useful lifetime, minimal shielding requirements, and oxide stability. LANL experience with the plutonium-238 isotope goes back many years to pioneering efforts associated with pacemaker development (Mullins 1972; Shupe 1970). Several rooms containing dozens of glove boxes in our-facility-are dedicated to processing plutonium-238. Processing capability includes production-scale operations for oxygen-16 isotope exchange of plutonium-238 oxide fuel (to reduce neutron emission from alpha-N reactions), pellet fabrication, fuel cladding, and testing. Over 200 General Purpose Heat Source (GPHS) units containing $\sim 150 \mathrm{~g} \mathrm{238} \mathrm{PuO}_{2}$ each have been fabricated over the last three years for Radioisotope Thermoelectric Generator (RTG) units. At the same time, dozens of smaller heat sources have been produced for use as Radioisotopic Heater Units (RHU).

Additional plutonium-238 fuel for future heat source production could come from various sources in the DOE complex. Many of these alternative feedstocks can be recovered and purified in a glove box environment.

\section{AOUEOUS PLUTONIUM CHEMISTRY}

Dissolution of high-fired plutonium-238 dioxide

The plutonium-238 oxide fuel used as feed for this study was fired at temperatures up to $1600^{\circ} \mathrm{C}$. Dissolution of plutonium oxide fired to these temperatures is very slow and often incomplete in refluxing nitric acid (Cleveland). Addition of a small amount of hydrofluoric acid aids oxide dissolution, but was too slow for our purposes. Our best dissolution results to date incorporate an initial milling of the ${ }^{238} \mathrm{PuO}_{2}$ feed in a high-energy ball mill. The milled oxide was stirred in a mixture 


\section{DISCLAMMER}

This report was prepared as an account of work sponsored by an agency of the United States Government. Neither the United States Government nor any agency thereof, nor any of their employees, make any warranty, express or implied, or assumes any legal liability or responsibility for the accuracy, completeness, or usefulness of any information, apparatus, product, or process disclosed, or represents that its use would not infringe privately owned rights. Reference herein to any specific commercial product, process, or service by trade name, trademark, manufacturer, or otherwise does not necessarily constitute or imply its endorsement, recommendation, or favoring by the United States Government or any agency thereof. The views and opinions of authors expressed herein do not necessarily state or reflect those of the United States Government or any agency thereof. 


\section{DISCLAIMER}

Portions of this document may be illegible in electronic image products. Images are produced from the best available original document. 
of nitric and hydrofluoric acids refluxing at ambient pressure. This provided good dissolution efficiency after 7-8 hours at reflux. Each dissolved batch contained from 18 to $65 \mathrm{~g}$ of $\mathrm{PuO}_{2}$.

Reagent grade chemicals were used to minimize introduction of contaminant elements. Teflon or polypropylene apparatus was used for handling ${ }^{238} \mathrm{Pu}$ solutions to avoid leaching silicates from glassware.

\section{Plutonium precipitation and conversion to oxide}

Several precipitation methods that have been used for purification and recovery of plutonium-238 were considered for this study. These include plutonium (III) oxalate, plutonium (IV) oxalate, plutonium (IV) peroxide, and plutonium (IV) hydroxide precipitations. Hydroxide precipitation would not be expected to provide selectivity with respect to metal impurities. Plutonium (IV) oxalate precipitation provides good selectivity in decontaminating plutonium from many elements, but requires close control of several parameters. Plutonium (IV) peroxide precipitation provides better decontamination from certain elements, but requires additional conversion steps to obtain the oxide. Plutonium (III) oxalate precipitation was selected because of simplicity, speed and adequacy of purification. In particular, plutonium (III) oxalate precipitation requires no temperature control, shows little detrimental effect from excess oxalic acid, and has a rapid reaction, precipitation, and filtration time.

The large amount of radiolysis associated with plutonium-238 complicates control of the Pu oxidation state in nitric acid. In general, the radiolysis of nitric acid produces a more oxidizing environment, and a larger proportion of Pu(VI) (Katz, 1986). The presence of additional oxidizing agents in the nitric acid increase the amount of reducing agents required to effect complete reduction to $\mathrm{Pu}(\mathrm{III})$. Others have observed that ${ }^{238} \mathrm{Pu}$ is best reduced to $\mathrm{Pu}(\mathrm{II})$ by combinations of "holding reagents" and "reducing agents" (Greinetz 1980; Burney 1984). Holding agents react quickly with nitrite and other oxidizing species, reducing the rate of $\mathrm{Pu}(\mathrm{III})$ reoxidation, while the reducing agent rapidly reduces $\mathrm{Pu}(\mathrm{VI})$ and $\mathrm{Pu}(\mathrm{IV})$ in solution to $\mathrm{Pu}$ (III). Hydroxylamine nitrate was used as the primary reducing agent, while either sulfamic acid or urea was the holding agent. One precipitation using only hydroxylamine nitrate as a reducing agent gave poor results. All steps were performed as rapidly as possible to minimize the effects of radiolysis. Precipitations varied from 9 to $30 \mathrm{~g}$ of $\mathrm{PuO}_{2}$ per batch.

For this study, recovered plutonium(III) oxalate was air-dried and then heated to dull red heat in a stainless steel, slip-top can on a hot plate for about 60 minutes to convert the material to the oxide. Heating for longer time produced no significant weight loss. While this heating method is adequate to produce plutonium oxide for analysis, heating to higher temperatures is required for plutonium oxide destined for use in GPHS programs.

\section{BESULTS}

Non-Actinide Element Decontamination

Table 1 shows analytical results for element impurities in the feed material and plutonium oxide produced by oxalate precipitation. The numbers in boldface type in Table 1 represent $\mu \mathrm{g} / \mathrm{g}$ observed values for the impurities. Italicized numbers indicate results that are at or below the indicated detection limits.

The first row in Table 1 lists the element limits in $\mu \mathrm{g} / \mathrm{g}$ that are specified in the GPHS standard (reference). Two different sources of plutonium-238 oxide fuel, as designated by Feed \#1 and Feed \#2, were utilized for the experiments. Analytical data from several plutonium(III) oxalate precipitation experiments are also shown. Good decontamination was achieved in all cases for silicon, phosphorus, chromium, iron and nickel, with somewhat poorer and mixed results for aluminum.

\section{Actinide Element Decontamination}

The first row in Table 2 lists the actinide impurities in $\mu \mathrm{g} / \mathrm{g}$ as specified by the GPHS standard. The numbers in boldface type in Table 2 represent values observed for the actinide impurities. Those numbers presented in standard type indicate results that are at or below the indicated detection limits. Among actinide impurities, uranium is of paramount concern as ${ }^{234} \mathrm{U}$ is the daughter product of ${ }^{238} \mathrm{Pu}$ by alpha decay. ${ }^{234} \mathrm{U}$ was by far the largest actinide impurity observed in the feed material. Good decontamination was achieved for $\mathrm{U}$, with modest decontamination also observed for $\mathrm{Np}$. Am and Th showed no significant decontamination from $\mathrm{Pu}$ under the conditions of plutonium (III) oxalate precipitation. As these actinides are well below the GPHS standard in the feed, they were not a major concern.

\section{Personnel Exposure}

This study and others (Shupe, 1970) have indicated that in the absence of fission products, significant quantities of plutonium-238 in solution may be safely handled in a glovebox environment equipped with proper shielding. Most of the gamma emission from plutonium-238 is of low energy and easily shielded. Most of the neutron emmission associated with plutonium-238 processing is produced by $(\alpha, n)$ reaction with light elements, spontaneous fission, and fast fission. The neutron output from $(\alpha, n)$ reactions can be minimized by avoiding light element contaminants, particularly $\mathrm{Be}, \mathrm{B}$ and $\mathrm{F}$. Additional neutron shielding will be incorporated on the glovebox to further reduce personnel neutron exposure for future work. Exposure from gamma can be further reduced by point-source shielding. 
Table 1 element results

Sum of

\begin{tabular}{|c|c|c|c|c|c|c|c|c|c|c|c|c|c|c|c|c|c|c|c|}
\hline & $\mathrm{Al}$ & $\mathrm{B}$ & $\mathrm{Be}$ & $\mathrm{Ca}$ & $\mathrm{Cd}$ & $\mathrm{Cr}$ & $\mathrm{Cu}$ & $\mathrm{Fe}$ & $\mathrm{Mg}$ & $\mathrm{Mn}$ & Mo & $\mathrm{Na}$ & $\mathrm{Ni}$ & $\mathrm{Pb}$ & $P$ & $\mathrm{Si}$ & $\mathrm{Sn}$ & $\mathrm{Zn}$ & non Actinides \\
\hline GPHS Std. & 150 & 5 & 5 & 300 & 50 & 250 & 100 & 800 & 50 & 50 & 250 & 250 & 150 & 100 & 25 & 200 & 50 & 50 & 2550 \\
\hline Feed \#1 & 145 & 5 & 1 & 9 & 10 & 390 & $l$ & 830 & 18 & 13 & 20 & 50 & 120 & 20 & 710 & 560 & 5 & 5 & 2558 \\
\hline Pdt. \# 1A & 200 & 5 & 1 & 3.5 & 10 & 285 & 1 & 335 & 10 & 9 & 20 & & 5 & 10 & 20 & 5 & 5 & 5 & . \\
\hline Pdt.\# IB & 34 & 5 & 1 & 65 & 10 & 19 & 1 & 67 & 10 & 2 & 20 & 50 & 9 & 10 & 20 & 53 & 5 & 5 & 377 \\
\hline Feed \#2 & 155 & 5 & 1 & 95 & 10 & 820 & 13 & 1500 & 10 & 18 & 20 & 50 & 455 & 20 & 20 & 850 & 5 & 23 & 4051 \\
\hline Pdt. \# 2A & 185 & 5 & 3 & 40 & 10 & 14.5 & 20 & 39 & 10 & 1.5 & 20 & 50 & 7.5 & 10 & \#\#\# & 7 & 5 & 5 & 436.5 \\
\hline Pdt. \# 2B & 155 & 5 & 3 & 40 & 10 & 19 & 18 & 78 & 10 & 3 & 20 & 50 & 14 & 10 & \#\#\# & 5 & 5 & 5 & 453 \\
\hline
\end{tabular}

Pdt. \# 2C

Pdt. \# 2D

Pdt. \# 2E 
TABLE 2. Actinide Impurities in Plutonium-238 Fuel

\begin{tabular}{|c|c|c|c|c|c|c|}
\hline & Am-241 & Np-237 & $\mathrm{Pu}-236$ & U-234 & Th & $\begin{array}{c}\text { Sum of } \\
\text { Actinides }\end{array}$ \\
\hline GPHS Std. & 5000 & 5000 & 2 & 5000 & 5000 & 10000 \\
\hline Feed \#1 & 373 & 978 & 1 & 14000 & 1600 & 16952 \\
\hline Pdt \# 1A & 342 & 936 & 1 & 2460 & 1600 & 5339 \\
\hline Pdt \# 1B & 351 & 237 & 1 & 580 & 1700 & 2869 \\
\hline
\end{tabular}

Feed \# 2

Pdt. \# 2A

Pdt. \# 2B

Pdt. \# 2C

Pdt. \# 2D

Pdt. \# 2E

\section{CONCLUSIONS}

NMT Division has expertise and facilities that make larger scale recovery and purification of plutonium-238 for oxide fuel a practical option. Additional supplies of plutonium-238 oxide fuel from many existing sources, including scrap and materials that fail the GPHS standard, can be recovered in a glovebox environment. For relatively pure ${ }^{238} \mathrm{PuO}_{2}$ feeds, including those with significant ${ }^{234} \mathrm{U}$ ingrowth, the plutonium (III) oxalate precipitation procedure is adequate to meet the GPHS fuel standard.

\section{Acknowledgments}

Acknowledgments to Keith Fife, Mark Dinehart, Steve Yarbro \& Steve Schreiber for helpful conversations. Thanks to Charles V. Puglisi, Carlos D. Dozhier, Christina M. Lynch, Paul F. Moniz, Robert W. Mathews, Richard T. Romero, and Mary Severinghausof LANL group NMT-9 for the help with hot jobs and sample removal. Thanks to Johnny N. Quintana, Margaret T. Trujillo and Nelson D. Stalnaker of LANL group CST-8 for radïochemical analysis of solutions. Thanks to numerous others in LANL groups CST-8 and CST-9 for elemental and radiochemical analysis of the plutonium-238 oxide products.

\section{References}

Burney, G. A., and Smith, P. K. (1984); "Controlled $\mathrm{PuO}_{2}$ Particle Size from Pu(III) Oxalate Precipitation". Dupont/Savannah River Laboratory Report DP-1689.

Cleveland, J. M. (1979); "The Chemistry of Plutonium", Published by The American Nuclear Society, 573-575.

Greinetz, R. M.; and Neal, D. H. (1980); "Plutonium(III) Oxalate Precipitation and Calcination Process for Plutonium Nitrate to Oxide Conversion". Rockwell International/Rocky Flats Plant Report RFP-2603.

Katz, J. J., Seaborg, G. T., Morss, S. R. (1984); "The Chemistry of the Actinide Elements", Second Edition. Published by Chapman and Hall Ltd., 1:825

Mullins, L. J. (1972); "Preparation and Development of Medical-Grade Plutonium-238 Fuels, July 1, 1967 - June 30, 1971". Los Alamos National Laboratory Report LA-4940.

Rogers, D. R., and Kokenge, B. R. (19xx); "Hydroxide and Oxalate ${ }^{238} \mathrm{PuO}_{2}$ Radioisotopic Fuel Processes at Moun Laboratory". : Mound Laboratory Report.

Shupe, M. W., Mullins, L. J., Morgan, A. N., Gonzales, A. L., Ogard, A. E., Valentine, A. M., Leary, J. A. (1970); "Operating Experience on an Economical Plutonium-238 Processing Facility". In Radiation Safety in Hot Facilities, IAEA-SM-125/45. 